\title{
Ludis Doctrina: Grupo de Pesquisa em Aprendizagem Conectada e Jogos
}

\author{
Ruy J. G. B. de Queiroz, Pasqueline Dantas Scaico, Lays Rosiene Silva, Ivson \\ Santos
}

Centro de Informática - Universidade Federal de Pernambuco (UFPE) - Av. Jornalista Anibal Fernandes - Cidade Universitária, Recife - PE - CEP: 50740-540, Brasil

$\{r u y, p d s$, lras, ihbs $\}$ ecin.ufpe.br

\section{Resumo}

As tecnologias do século XXI têm influenciado fortemente como as pessoas se comportam, pensam, se relacionam entre si e aprendem, influências estas que têm provocado mudanças culturais. Diante deste cenário, o conceito de aprendizagem tem sido entendido como um fenômeno dinâmico, que reflete o estado de as pessoas se tornarem, no qual até mais importante do que a base de conhecimento existente é a capacidade que temos de nos adaptar e aprender a aprender, entre outras. Assim, pesquisar aprendizagem exige que os estudos utilizem maiores escalas de tempo, considerem os múltiplos espaços que o aprendiz frequenta, sejam eles formais e informais, e como as novas mídias estabelecem ambientes convidativos para que as pessoas se engajem e assumam maior controle sobre o seu processo de aprender, possam desenvolver a sua inteligência e persigam seus interesses pessoais.

Nesse contexto, o grupo Ludis Doctrina, criado em 2013 no Centro de Informática pelo professor Ruy J. G. B. de Queiroz, tem por objetivo realizar pesquisas de natureza sociocultural, que são orientadas por uma perspectiva ecológica. $O$ grupo também se concentra no estudos dos jogos como espaços de possibilidades para aprendizagem. Atualmente, é composto por uma estudante de doutorado, Pasqueline Scaico, e dois estudantes de mestrado, Lays Rosiene Silva e Ivson Santos, que desenvolvem os seguintes projetos de pesquisa, respectivamente: i) Trajetórias de aprendizagem na era digital usando vídeo games, ii) Escalabilidade do Modelo da Quest to Learn e iii) O Conceito de Fluxo (Psicológico) como Ferramenta de Engajamento em Aprendizagem Baseada em Jogos. O grupo possui financiamento do Conselho Nacional de Desenvolvimento Científico e Tecnológico (CNPq) para o projeto: "Um estudo sobre aprendizagem na era digital e o uso efetivo das tecnologias na escola" (Proc. 486307/2013-1). O Ludis Doctrina possui uma publicação internacional, quatro nacionais e dois artigos publicados em jornal de grande circulação.

Em abril de 2014, o grupo realizou o I Workshop on Connected Learning and Games for Learning ${ }^{1}$, no Centro de Informática da Universidade Federal de Pernambuco, ocasião na qual foi possível, entre outras coisas, dialogar com membros da escola nova iorquina Quest to Learn ${ }^{2}$, que recebe aporte do Institute of Play e tem utilizado os princípios do Game Design de jogos como estratégia para alavancar o processo de aprendizagem dos seus estudantes.

\footnotetext{
${ }^{1} \mathrm{http}: / /$ ludisdoctrina.blogspot.com.br/

${ }^{2}$ http://q21.org
} 